\title{
The Chest CT Finding of Pleural Plaques and Asbestosis in Lung Cancer Patients: A Case Study
}

\author{
Aziza Ghanie Icksan, MD Sp.Rad (K), ${ }^{1}$ Anna Suraya, MD, MKK, SpOk, ${ }^{2}$ Nurul Hanifah, MD, ${ }^{3}$ \\ Elisna Syahruddin, MD, Sp.P (K) and Astrid Sulistomo, MD, MPH, SpOk ${ }^{5}$ \\ ${ }^{1}$ Department of Radiology Persahabatan, Nasional Respiratory Referral Hospital Jakarta and Faculty of Medicine UPN Veteran Jakarta, Indonesia \\ ${ }^{2}$ Center for International Health CIHLMU, University Hospital, LMU Munich, Germany \\ and Occupational Health and Safety Program, Binawan University, Jakarta, Indonesia \\ ${ }^{3}$ Occupational Medicine and Environmental Study Centre, Jakarta, Indonesia \\ ${ }^{4}$ Division of Thoracic Oncology Department of Pulmonology Faculty of Medicine, Universitas Indonesia Persababatan Hospital, Jakarta, Indonesia \\ ${ }^{5}$ Occupational Medicine Specialist, Universitas Indonesia Academic Hospital, Jakarta, Indonesia
}

\begin{abstract}
A sixty-eight years old man was referred to the hospital for evaluation of lung adenocarcinoma treatment. Chest computed tomography (CT) imaging showed lung nodule, pleural plaques, ground-glass opacity, and parenchymal bands related to asbestosis. Pleural plaques are the proxy of asbestos exposure, and asbestosis is lung parenchymal fibrosis caused by asbestos. The interview revealed that the patient had worked as an owner of a construction firm for more than 37 years. Construction workers are at high risk of getting asbestos-related diseases because some building materials have asbestos.
\end{abstract}

This case study aimed to describe chest CT findings of asbestosis and pleural plaques that suggest the presence of asbestos exposure in a lung cancer case. This case showed the pivotal role of chest CT to define asbestos-related lung diseases and a structured interview to obtain past asbestos exposure.

Keywords: lung cancer, asbestos, construction worker, chest CT

\section{BACKGROUND}

This case report aimed to demonstrate the presence of asbestosis and pleural plaques showed by chest CT that represented past asbestos exposure in lung cancer cases. To the best of the authors' knowledge, to this day, there is no study reporting asbestos-related lung cancer in Indonesia. Therefore, it is hoped that this case report will assist others in making a diagnosis of occupational asbestosrelated lung cancer in the future. Moreover, the study also demonstrated the need for a multidisciplinary approach involving pulmonologists, radiologists, and occupational medicine physicians.

\section{CASE PRESENTATION}

A sixty-eight-year-old Java ethnic man was brought to the National Referral Hospital for Lung Diseases, Persahabatan Hospital for lung cancer treatment, where he completed first-line chemotherapy. The patient had no clinical complaints. Family history showed that his mother died of breast cancer.

Chest computed tomography (CT) scan with contrast Department of Radiology

Persahabatan Nasional Respiratory Referral Hospital Jakarta Faculty of Medicine UPN Veteran Jakarta, Indonesia 16, Jl. Persahabatan Raya No.1, RT.16/RW.13, Rawamangun Pulo Gadung, East Jakarta, Jakarta 13230

Email: azizagicksan@yahoo.com 

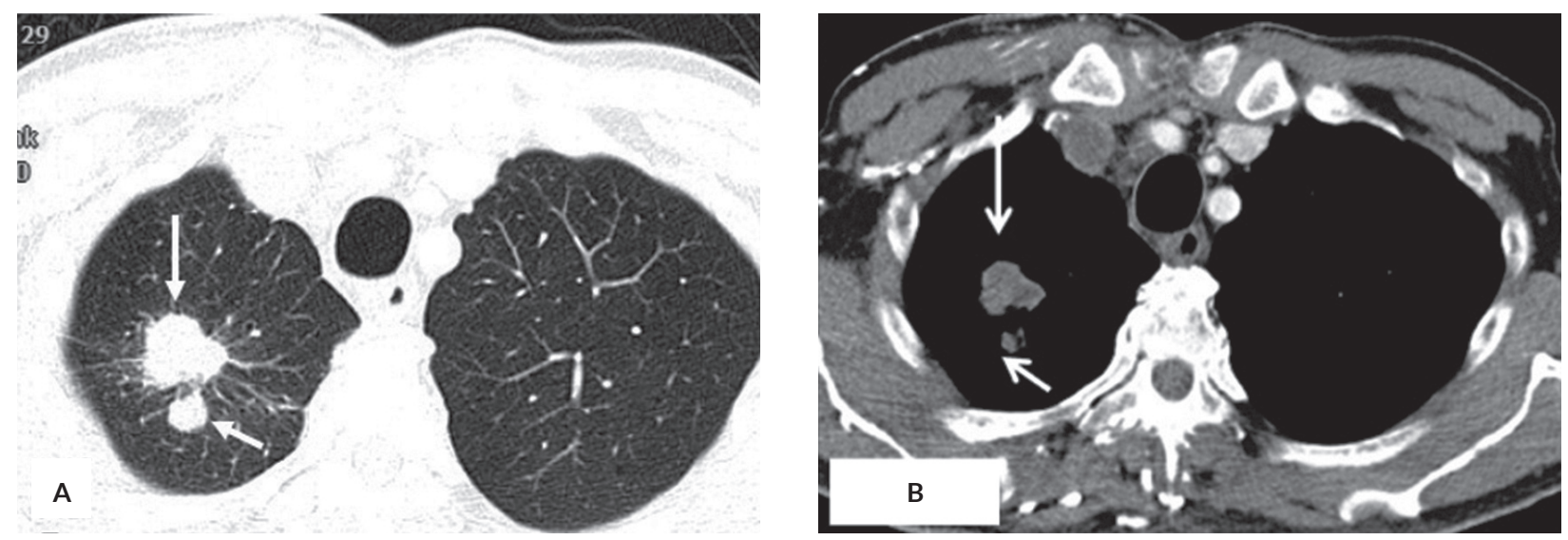

Figure 1. Enhanced chest CT: (A) lung window shows right upper lung lobe nodule with a size of $2.5 \times 2 \mathrm{~cm}$ (long arrow) and satellite nodule of $1 \mathrm{~cm}$ in diameter (short arrow). The nodules are lobulated, had speculated margins, and pleural tails consistent with malignant morphology. (B) Mediastinal window show enhancement after contrast (arrow).
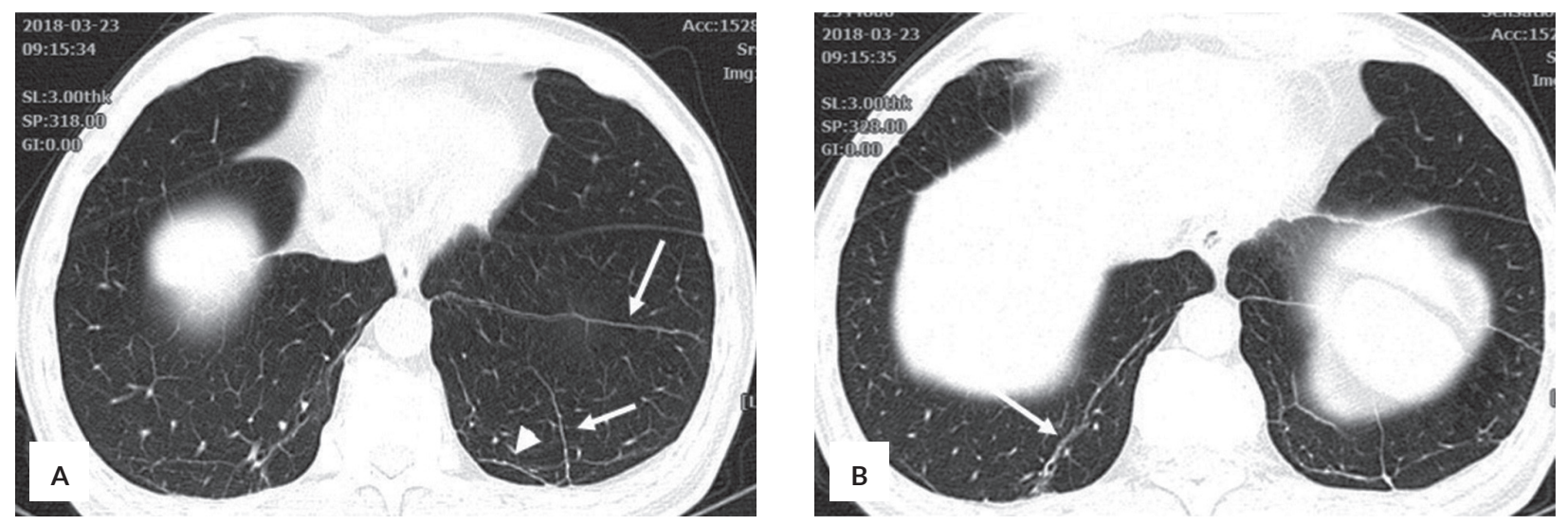

Figure 2. Axial chest CT shows (A) Parenchymal bands located in the left lower lung lobe (arrow) and curvilinear opacity near the parenchymal bars (head arrow). (B) Parenchymal band in the right lower lung lobe (arrow).

$2.5 \mathrm{~cm}$ and satellite nodules of $1 \mathrm{~cm}$ in diameter. The nodules were lobulated and had speculated margin and pleural tail consistent with malignant morphology (Figure 1). Also, we observed pleural plaques, parenchymal bands, and ground-glass opacity in both lower lobes of the lungs. Axial chest CT scan showed parenchymal bands as linear density extending from the pleural surface through the lung with length $6 \mathrm{~cm}$ and $11 \mathrm{~cm}$ located in the left lower lung lobe. Subpleural curve linear opacity of $2 \mathrm{~cm}$ in length was seen near the parenchymal bands (Figure 2). The coronal reconstruction revealed parenchymal changes adjacent to the pleura (typical table land-shaped pleural plaques) and ground-glass opacity in both lower lung lobe (Figure 3A). Thin pleural plaques with tapering margins were observed in both lower lung zone (Figure 3B). Those chest CT findings are the characteristic findings of asbestosis. Those findings could not be observed in the chest CT scan after three months of chemotherapy because the patients had pleural effusion in both lower lungs obscuring the pleural changes. A chest $\mathrm{CT}$ scan taken three months earlier showed the same pattern of asbestos-related pleural and parenchymal changes (Figures 4 and 5).

Cytology from transbronchial needle aspiration exhibited adenocarcinoma, and epidermal growth factor receptor (EGFR) mutation test resulted in tumor percentage contents around 200 cells with no mutation detected.

The patient had been an owner of a construction company for more than 37 years. He was involved in a wide range of construction work, from simple house renovation to big projects like building apartments, roads, and bridges. The patient worked to manage the whole construction project process from providing the document, preparing material, and directly involved in the supervision of work projects. He worked on an average of 12 hours per day and 5 to 7 days a week with no regular leave.

Being directly involved in construction projects had placed the patient in close contact with asbestos-containing building materials.

In Indonesia, there is no report of asbestos measurements in the construction industries. 

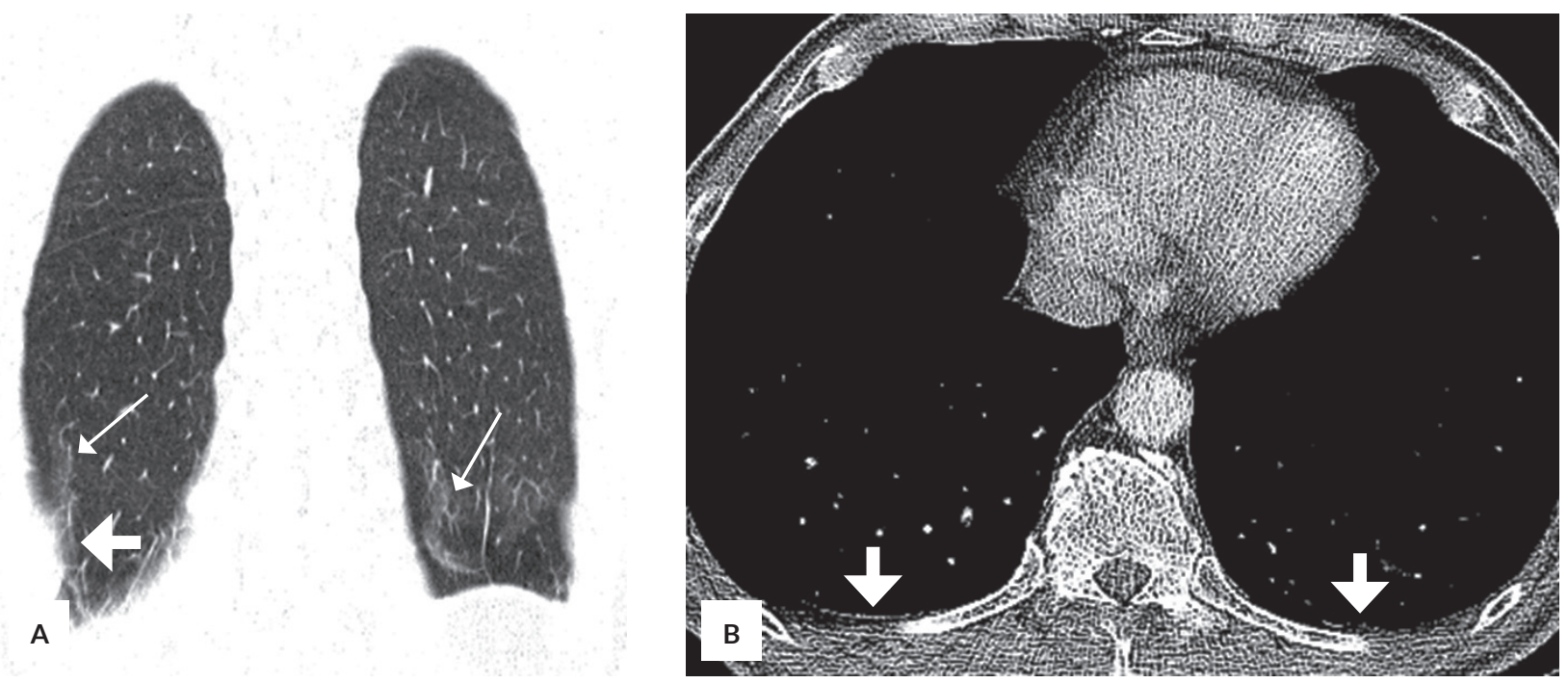

Figure 3. (A) Chest CT with coronal reconstruction shows typical tableland-shaped pleural plaques (short arrow) and ground-glass opacity in both of lower lung lobe (long arrow). (B) Axial chest CT shows pleural plaques with tapering margins in both of lower lung zones (arrow).
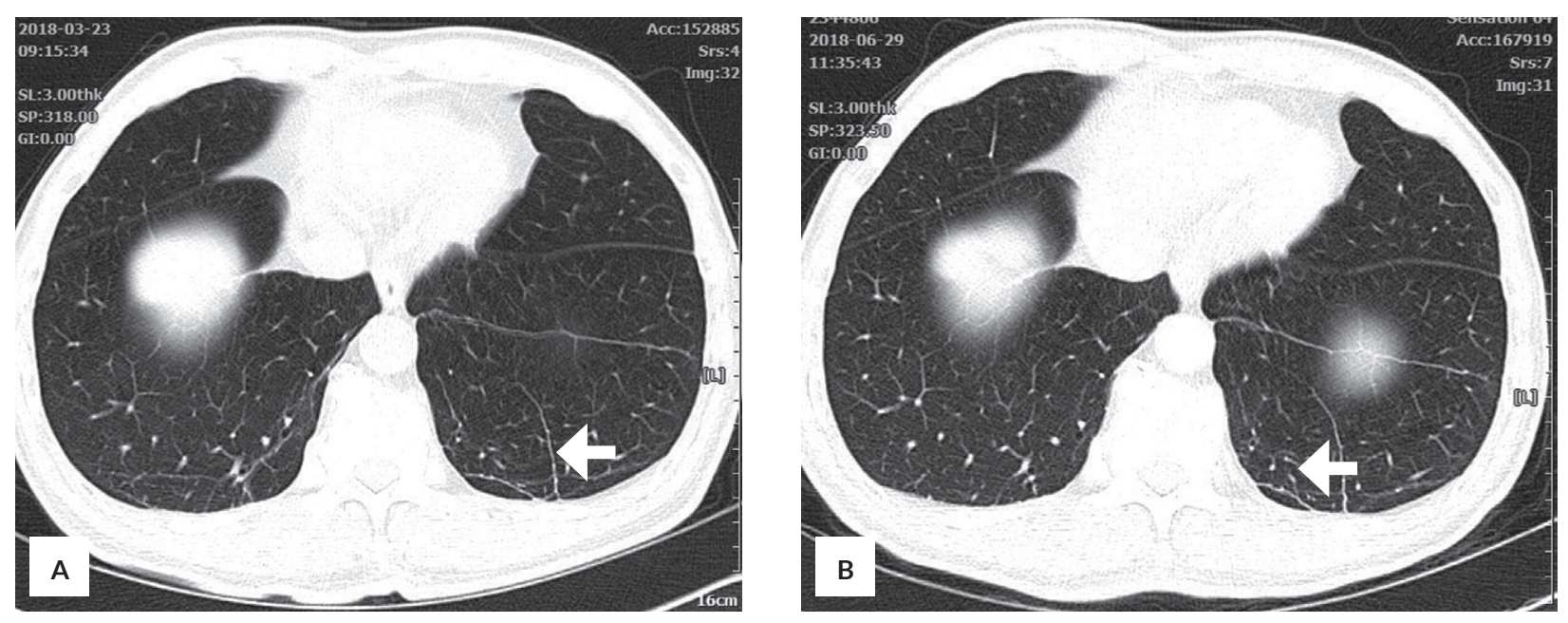

Figure 4. Axial chest CT of parenchymal bands taken in three months separated time. (A) Chest CT taken on March 2018. (B) Chest CT taken on June 2018.
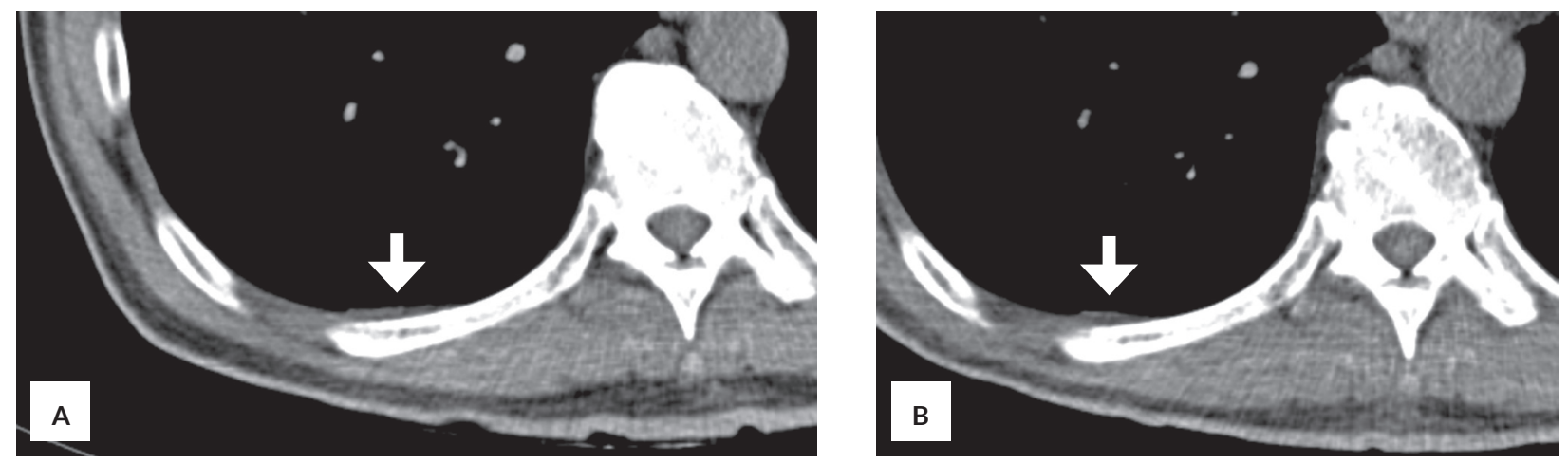

Figure 5. Axial chest CT of pleural plaques taken in three months separate time. (A) Chest CT taken on March 2018. (B) Chest CT taken on June 2018. 
There was no environmental exposure reported. He reported a history of smoking four cigarettes a day for five years. No family member has a smoking habit.

Informed consent was obtained from the patient for the publication of this case report.

\section{DISCUSSION}

The suspicion that asbestosis might be linked to lung cancer began to emerge in the 1930s. In 1935, Gloyne was the first to report cases suggestive of asbestos-related lung cancer, two instances of small-cell carcinoma in women with asbestosis. ${ }^{1}$ Later, in 1955, Doll proved the causal association between asbestosis and lung cancer. ${ }^{2} \mathrm{~A}$ study from Indonesia by Suraya et al. reported that lung cancer was doubled for workers exposed to asbestos than non-exposed workers. The risk of lung cancer among construction workers was doubled compared to other workers. ${ }^{3,4}$

This case was the first suggested asbestos-related lung cancer notified incidentally in Indonesia. Although the country does not have any criteria for defining an asbestosrelated lung cancer, past asbestos exposure was found by finding pleural plaques and asbestosis in chest CT. The occupational history strengthens the evidence of past asbestos exposure.

In this case, the characteristic radiographic finding may be enough to establish exposure. Many studies demonstrated that pleural plaque is a useful marker of asbestos exposure that presents in approximately 60 percent of persons with occupational asbestos exposure., ${ }^{5,6}$ In evaluating pleural plaques, conventional $\mathrm{CT}$ is more superior to chest film. On CT, pleural plaques appear as focal pleural thickening with a linear, band-like, or nodular appearance. The pleural plaques can affect adjacent lung parenchyma and cause pulmonary subpleural curvilinear line., ${ }^{7,8}$

Pleural plaques usually present multiple lesions involving the parietal pleura, commonly along with the sixth to ninth ribs. ${ }^{9}$ They are typically bilateral, even though a third of cases involve unilateral hemithorax. ${ }^{10}$ The most common site is the chest wall, followed by the diaphragm and the mediastinum.

Asbestosis is a lung parenchymal fibrosis that occurred in the asbestos-exposed lung. Studies reported that the cumulative exposure of around 10 to 25 fiber years could cause asbestosis. Conventional radiographs are relatively insensitive in detecting early asbestosis and tend to miss the presence of the disease. ${ }^{11}$ It is well recognized that high-resolution computed tomography (HRCT) gives a clear view of both parenchymal and pleural abnormalities. ${ }^{11,12}$

The amount of asbestos exposure in this patient can be estimated by reconstructing exposure measurement through literature, which is asbestos job exposure matrices (JEM) established in many countries. As for Indonesia, asbestos JEM cannot be established due to the unavailability of airborne asbestos concentration data. The asbestos JEM from
Korea was adopted to determine the amount of asbestos exposure in this patient. According to the JEM developed by Choi et al. in Korea, a construction worker is included in exposure group 29 (EG29) under the industry of apartment building construction. It was reported that from 1996 to 2006, asbestos concentration in construction industries ranged from 0.004 to $0.32 \mathrm{fiber} / \mathrm{ml}$ with weighted arithmetic mean (WAM) concentration was $0.0393 \mathrm{fiber} / \mathrm{mL} .{ }^{13}$ This patient worked in construction projects from 1978 until 2015, with workhours per day was around 12-hours, 5 to 7 days a week.

The cumulative asbestos exposure expressed in fiber-years is fiber concentration and the total duration of exposure. One standard fiber year is defined as exposure during an 8-hour shift over 240 workdays and spread over 48 weeks with a standard airborne fiber concentration of one fiber per cubic centimeter or $1 \times 10^{\wedge} 6$ fibers cubic meter. ${ }^{7}$ Given one standard fiber year, as explained before, assuming that patient's work for 12 hours 5 days a week, the minimal exposure is 0.22 fiber year ( 37 years x 12/8 hours x 0.004 fiber $/ \mathrm{mL}$ ). The maximal exposure is 17.26 fiber years ( 37 years x $12 / 8$ hours x 0.32 fiber $/ \mathrm{mL}$. As Indonesia's construction projects are still far from having a good quality of protection to workers, the construction workers are expected to be exposed to a higher concentration of asbestos. The retention time of asbestos fibers in his lung was calculated as 40 years (1978-2018).

Data from Foreign Trade Statistic showed more than one million tons of asbestos industrialized in Indonesia in the last ten years, mostly as the raw material of the roof, cement, platform, and partition. There are 17 asbestos factories for building material purposes and 16 asbestos manufacturing industries producing asbestos-containing products for other purposes in Indonesia. It was also reported that at least 411 companies imported asbestos-containing materials. Lately, it is said that around $9.8 \%$ of houses in Indonesia use asbestos roofing, which indicates a high probability that construction workers to work with asbestoscontaining materials. ${ }^{14}$

\section{CONCLUSION}

This case report showed a case of asbestos-related lung cancer that can be determined by the presence of pleural plaques and asbestosis in a CT scan. Occupational history taking could reveal past asbestos exposure that increases lung cancer risk among workers exposed to it. Strengthening occupational safety and health controls, particularly in the asbestos industry and construction industry, are necessary to protect workers from lung cancer and other asbestos-related diseases. This study recommends further epidemiological and experimental studies regarding asbestos exposure and its effect.

\section{Statement of Authorship}

All authors participated in the data collection and analysis and approved the final version submitted. 


\section{Author Disclosure}

All authors declared no conflicts of interest.

\section{Funding Source}

This study was self-funded.

\section{REFERENCES}

1. Gloyne SR. Two Cases of Squamous Carcinoma of the Lung Occurring in Asbestosis. Tubercle [Internet]. 1935 [cited 2019 Jan 5];17:5-10. Available from: https://www.cabdirect.org/cabdirect/ abstract/19362700526

2. Doll R. Mortality from lung cancer in asbestos workers 1955 . Br J Ind Med [Internet]. 1993 Jun [cited 2019 Jan 30];50(6):485-90. Available from: https://www.ncbi.nlm.nih.gov/pmc/articles/PMC1035472/

3. Suraya A, Nowak D, Sulistomo AW, Ghanie Icksan A, Syahruddin E, Berger U, et al. Asbestos-Related Lung Cancer: A HospitalBased Case-Control Study in Indonesia. International Journal of Environmental Research and Public Health [Internet]. 2020 Jan [cited 2020 Jan 20];17(2):591. Available from: https://www.mdpi.com/ $1660-4601 / 17 / 2 / 591$

4. Suraya A, Nowak D, Sulistomo AW, Icksan AG, Berger U, Syahruddin E, et al. Excess Risk of Lung Cancer Among Agriculture and Construction Workers in Indonesia. Annals of Global Health [Internet]. 2021 Jan 6 [cited 2021 Jan 25];87(1):8. Available from: http://www.annalsofglobalhealth.org/articles/10.5334/aogh.3155/

5. Diagnosis and Initial Management of Nonmalignant Diseases Related to Asbestos. American Journal of Respiratory and Critical Care Medicine [Internet]. 2004 Sep 15 [cited 2017 Apr 29];170(6):691715. Available from: http://www.atsjournals.org/doi/abs/10.1164/ rccm.200310-1436ST

6. Ultra low dose CT screen-detected non-malignant incidental findings in the Western Australian Asbestos Review Programme - Murray 2016 - Respirology - Wiley Online Library [Internet]. [cited 2019 Jan 4]. Available from: https://onlinelibrary.wiley.com/doi/full/ 10.1111/resp. 12826
7. Elshazley M, Shibata E, Hisanaga N, Ichihara G, Ewis AA, Kamijima $\mathrm{M}$, et al. Pleural Plaque Profiles on the Chest Radiographs and CT Scans of Asbestos-exposed Japanese Construction Workers. Industrial Health [Internet]. 2011 [cited 2019 Jan 4];49(5): 62633. Available from: http://joi.jlc.jst.go.jp/JST.JSTAGE/indhealth/ MS1268?from=CrossRef

8. Kim Y, Myong J-P, Lee JK, Kim JS, Kim YK, Jung S-H. CT Characteristics of Pleural Plaques Related to Occupational or Environmental Asbestos Exposure from South Korean Asbestos Mines. Korean Journal of Radiology [Internet]. 2015 Oct [cited 2017 Aug 8];16(5):1142. Available from: https://www.ncbi.nlm.nih.gov/ pmc/articles/PMC4559786/

9. Fletcher DE, Edge JR. The early radiological changes in pulmonary and pleural asbestosis. Clin Radiol. Jan 1;21(4):355-65.

10. Gevenois PA, Vuyst PD, Dedeire S, Cosaert J, Weyer RV, Struyven $\mathrm{J}$. Conventional and high-resolution $\mathrm{CT}$ in asymptomatic asbestosexposed workers. Acta Radiol. Jan 1;1994:226-9.

11. Asbestosis Imaging: Practice Essentials, Radiography, Computed Tomography. 2019 Nov 12 [cited 2020 Sep 7]; Available from: https://emedicine.medscape.com/article/352900-overview

12. Kusaka, Yukinori, Hering, Kurt G., Parker, John E. International Classification of HRCT for Occupational and Environmental Respiratory Diseases. Springer New York; 2005.

13. Choi S, Kang D, Park D, Lee H, Choi B. Developing Asbestos Job Exposure Matrix Using Occupation and Industry Specific Exposure Data (1984-2008) in Republic of Korea. Saf Health Work [Internet]. 2017 Mar [cited 2017 Sep 10];8(1):105-15. Available from: http://www.ncbi.nlm.nih.gov/pmc/articles/PMC5355542/

14. Badan Pusat Statistik [Internet]. [cited 2017 Aug 8]. Available from: https://www.bps.go.id/ 